\title{
AMERICAN STRATEGY: \\ ISSUES AND ALTERNATIVES \\ FOR THE QUADRENNIAL DEFENSE REVIEW
}

Steven Metz

September 2000 